\title{
Chapter 18 \\ Work and Learning Balance \\ for the Post-COVID-19 Era: Insights \\ from the Republic of Korea
}

\author{
Chan Lee
}

\section{Abbreviations}

COVID-19 coronavirus disease

HRD human resources development

ILO International Labour Organization

OECD Organisation for Economic Co-operation and Development

OJT on-the-job training

WLB work and learning balance

\subsection{Introduction}

The coronavirus disease (COVID-19), the pandemic that has snatched our daily lives away from us, is creating a global crisis. In the Republic of Korea, based on data as of 13 April 2020, new applicants for job-seeking support had increased $24.8 \%$ from 31,000 in March 2019 to 156,000 in March 2020 (Ministry of Employment and Labor 2020). Even in the United States, within 5 weeks after 16 March 2020, 26.5 million people had lost their livelihoods. On 1 April 2020, the International Labour Organization (ILO) put out the grim prospect that by the second quarter of 2020, labor hours will decrease by $6.7 \%$ and 195 million people would lose their jobs (ILO 2020). According to Statistics Korea's July Employment Trend, the number of employed workers in July 2020 is the first since the 2007-2008 global financial crisis to have decreased for 5 months straight, while the unemployment rate reached its highest in 21 years (Song 2020).

\footnotetext{
C. Lee (西)

Career Development Center, Seoul National University, Seoul, Republic of Korea

e-mail: chanlee@snu.ac.kr
} 
Such pessimistic transitions are not confined to the labor market. Socioeconomic change is also very much apparent. Financial sectors, especially profitability of banks, have deteriorated considerably because of the decrease in interest rates and the increase in loan delinquencies as a result of the economic recession from COVID-19. The manufacturing industry is in no better position. Performance of general manufacturers (of cars, cellphones, displays, and so on) is worsening. Meanwhile, aviation and oil industries are also suffering blows from the pandemic (Yang 2020).

COVID-19 has brought notable changes into education as well. In the Republic of Korea, 10 million students from elementary to university level have participated in distance learning, and all formal curricula have been converted from offline to online (Fig. 18.1). According to the data and analytics platform AppAnnie, the number of mobile educational application downloads for the first quarter of 2020 has increased $90 \%$ compared to the first quarter of 2019 (Yang 2020). In a research by ILO, United Nations Educational, Scientific and Cultural Organization (UNESCO), and World Bank Group, among 1349 respondents from vocational education and training providers, ministries of labor and education, employers, and labor organizations from 126 countries, $64 \%$ replied to have proceeded with their education by turning fully remote, while $16 \%$ answered that their education was cancelled due to COVID-19 (ILO, UNESCO, and WBG 2020).

These clearly show that COVID-19 not only impacted the society, economy, and culture, but education as well. As the changes and new environment brought in by a virus that nobody expected become the norm, it is urgent to exert multilateral effort to cope with these aberrations.

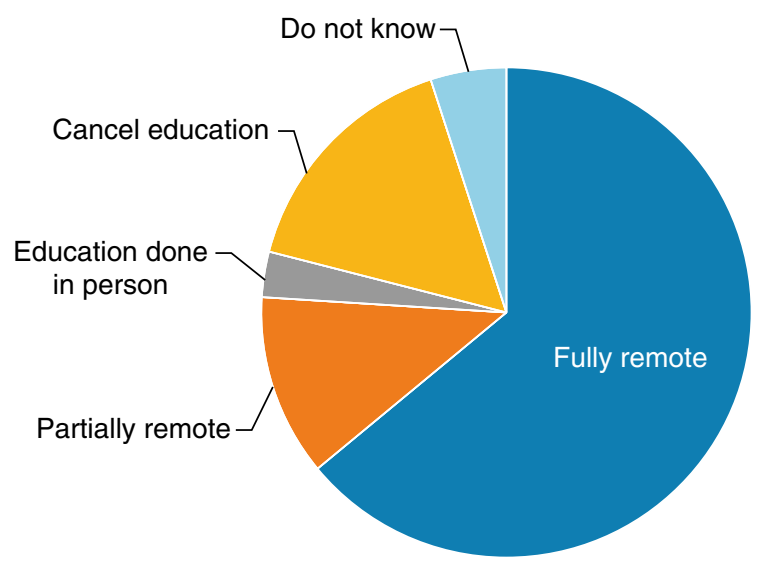

Fig. 18.1 How education was provided after elevation of COVID-19 alert level to "serious" (red) stage (\%) (In the Republic of Korea, 10 million students from elementary to tertiary level have participated in online learning). COVID-19 = coronavirus disease. Source Lee, C., and B. Park. 2020. Post COVID-19, survey on the actual condition of Korea about work \& learning balance (WLB). Paper presented in The Korean Society for Human Resource Development Annual Conference. 12 June 2020, Korea 


\subsection{The Reality of Work and Learning Balance in the Republic of Korea}

Significant changes are occurring within the purview of human resource development (HRD) in this COVID-19 era. A substantial number of in-person educational assemblies are being cancelled while remote work trend is rapidly expanding. In order to figure out the reality of this massive transition, our research team from Seoul National University investigated the state of HRD before and after COVID-19 (Lee and Park 2020). ${ }^{1}$ We set 23 February 2020 as the starting point, the day when the government announced it was raising the COVID-19 crisis alert to level 3 or "red" (serious). From this central date, the team split the timeline into two sections, before COVID-19 and after COVID-19. We asked questions for each division using a structured survey of 213 people from the Republic of Korea who were either in charge of human resource management and/or HRD (Fig. 18.2).

\subsubsection{Number and Duration of Training Sessions}

Prior to COVID-19, an average of seven training sessions (33.5\%) were held per quarter and were at least 20 hours in duration (32.1\%). However, after the alert level was elevated to "red," $34.3 \%$ of the respondents answered that no quarterly training sessions were held; and $42.5 \%$ answered that on average, 1-2 sessions per quarter were held. Meanwhile, the proportion of those who answered that the sessions
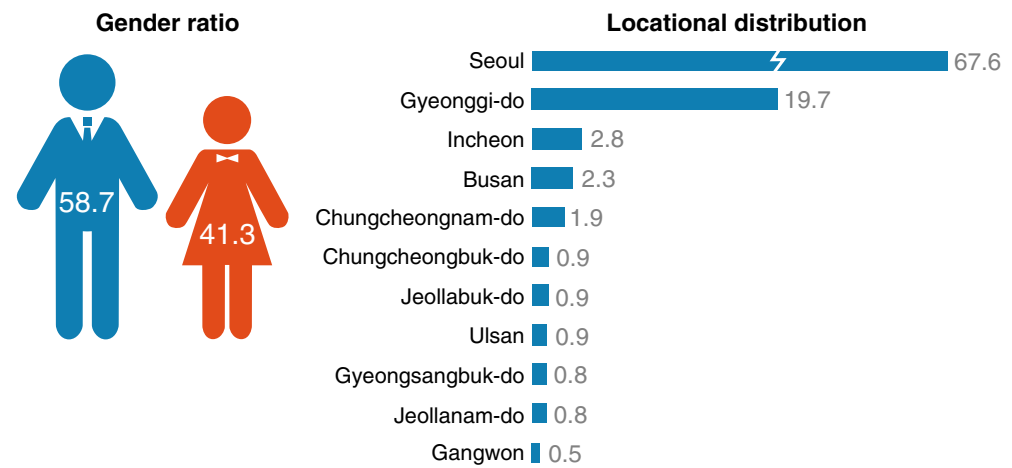

Fig. 18.2 Distribution by sex and location of respondents (\%) (Respondents were in charge of human resource management and/or human resource development). Note $N=213$. Source Lee, $\mathrm{C}$., and B. Park. 2020. Post COVID-19, survey on the actual condition of Korea about work \& learning balance (WLB). Paper presented in The Korean Society for Human Resource Development Annual Conference, Republic of Korea, 12 June

\footnotetext{
1"WLB" is a compound word meaning work-learning balance. Source Lee, C. 2020. Presentation in a virtual ATD 2020 Conference, 4 June 2020, based on Lee and Park (2020).
} 
lasted for more than 20 hours decreased greatly from 32.1 to $8.5 \%$; while $27.8 \%$ of the respondents answered that theirs lasted for 1-3 hours; and 37.8\% reported 4-7 hours. These replies suggest that the duration of the quarterly training sessions have decreased significantly (Fig. 18.3).

\subsubsection{Type of Training}

The difference between the conditions prior to and post-COVID-19 alert level "red" can also be seen from the field and the form of training held on the corresponding times. Prior to elevation to "red," trainings were held mostly on-the-job (OJT) at $58.5 \%$ and as position training at $30.2 \%$; however, after the elevation, the number for those training areas slightly decreased ( $45.8 \%$ for OJT, $16.5 \%$ for position training). In other areas of training (e.g., legal training, leadership training, organization invigoration training, etc.) the number of trainings increased by $6.5 \%$ in 2020 compared to $23.1 \%$ in 2019 as face-to-face training greatly decreased and turned into online sessions (Fig. 18.4).

\section{Average Frequency of Quarterly Training Sessions}

Before Alert Level "Red" vs. After Alert Level "Red"
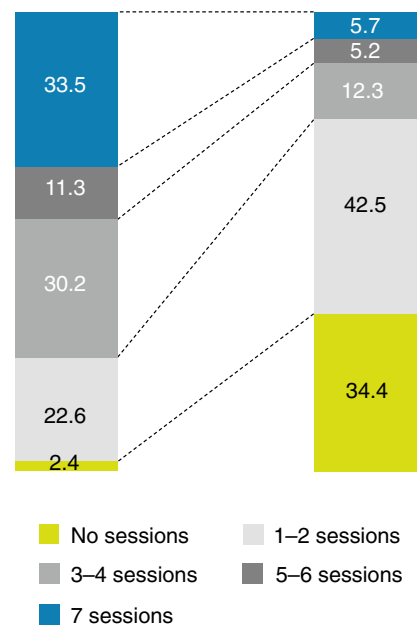

\section{Average Duration of Quarterly Training Sessions}

Before Alert Level "Red" vs. After Alert Level "Red"

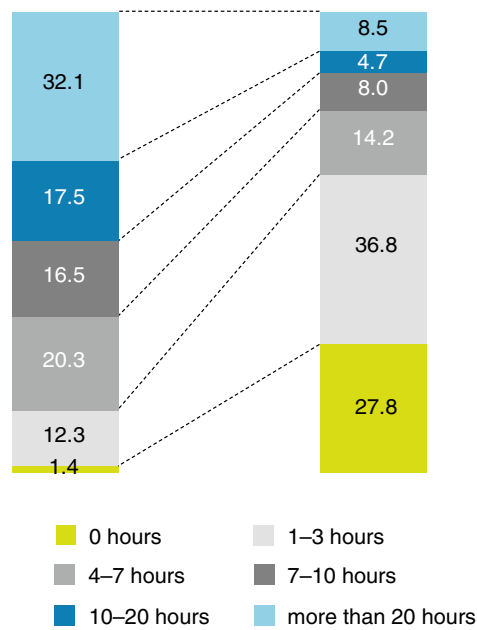

Fig. 18.3 Comparison between average number and duration of quarterly training sessions held before and after elevation of alert level to "red" (frequency, hours) (From 20 hours, training sessions in the Republic of Korea declined to as low as 1-3 hours from 20 hours during the coronavirus disease pandemic). Source Lee, C. 2020a. Present and future of HRD. Paper presented in the HRD Conference, Human Resources Development Service of Korea, Republic of Korea, 10 September 
Field of Training Held

Before Alert Level "Red" vs. After Alert Level "Red"

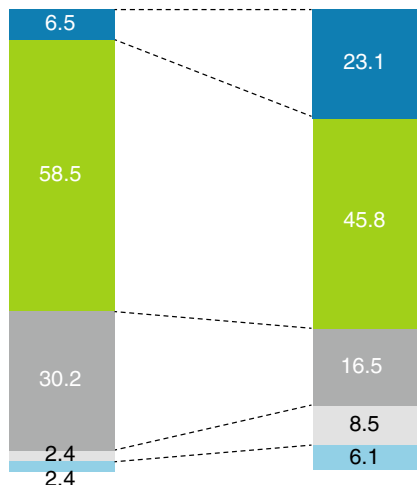

Language $\quad$ Liberal Arts
Position Training $\quad$ On-the-Job Training
Other
Form of Training

Before Alert Level "Red" vs. After Alert Level "Red"

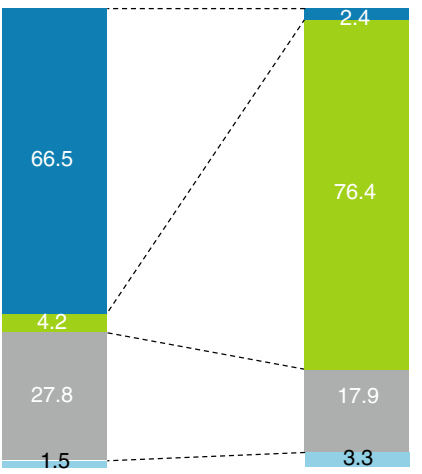

Other In-person+Online(Blended)

Online In-person(Offline)

Fig. 18.4 Comparison between field and form of training before and after the elevation of alert level to "red" (\%) (Face-to-face training greatly decreased and turned into online sessions during the coronavirus disease pandemic). Note In the "field of training" panel, "other" comprises legal training (security, prevention of sexual harassment); leadership training; organization invigoration, and so on. Source Lee, C. 2020a. Present and future of HRD. Paper presented in the HRD Conference, Human Resources Development Service of Korea, Republic of Korea, 10 September

\subsubsection{Education Methods}

As to the education method used during the training sessions, prior to the elevation of the alert level, the training method consisted mostly of lectures, discussions, and debates, and were practice-oriented. After the elevation, discussions and practical experience-oriented training decreased sharply. An interesting point to note is the visible pattern (from 6.6 to $>15.6 \%$ ) in the relative weight that OJT held within the corporate environment before and after the elevation. Since collective training and other human-to-human, interaction-based trainings were either being cancelled or postponed due to COVID-19, "learning within the workplace" was instead activated. Nevertheless, there is a high possibility that this is not a systemized OJT but probably a disorganized one (Fig. 18.5).

\subsubsection{Keywords}

The positive and negative experiences on HRD before and after the elevation to alert level "red" revealed that the keywords for positive experiences are "communication 


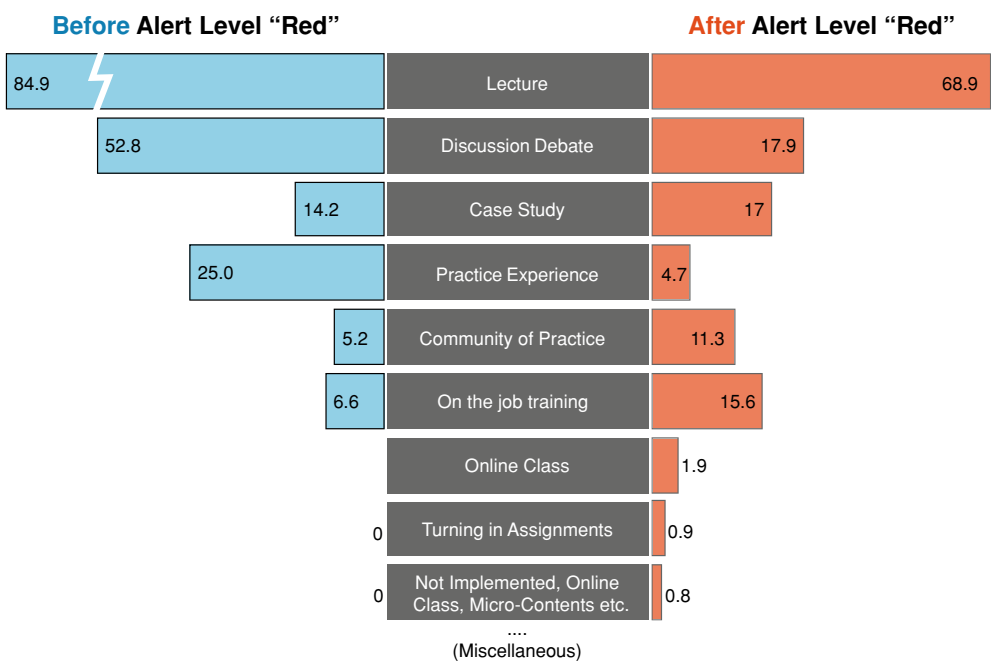

Fig. 18.5 Comparison between educational method used before and after the elevation of alert level to "red" (\%, repeated response) (Since collective training and other personal, interaction-based trainings were either being cancelled or postponed due to coronavirus disease, "learning within the workplace" was activated). Source Lee, C. 2020a. Present and future of HRD. Paper presented in the HRD Conference, Human Resources Development Service of Korea, Republic of Korea, 10 September

and/or networking" (30 cases); "offline, face-to-face, assembly training" (28 cases); and "capacity development" (15 cases). On the other hand, "time, budget deficit" (39 cases); "convention and/or one-sided" (24 cases); "inadequate measure of effectiveness" (19 cases); and "inefficient, shortage in outcome" (14 cases) are the keywords for negative experiences (Fig. 18.6).

In addition, "online, non-contact, remote learning" (76 cases); "new change" (16 cases); and "effectiveness" (12 cases) were keywords for positive experiences. For negative experiences, the keywords are "lack of interaction" (31 cases); "lack of learning opportunity" (25 cases); and "prohibition of assembly education" (16 cases) (Fig. 18.7).

\subsubsection{Prearranged Education}

For prearranged education, after the elevation of alert level to "red," most education programs were either postponed $(49.8 \%)$ or cancelled altogether $(27.7 \%)$. However, even if the program was still continued, it was done from one's own seat $(38.5 \%)$ or in one's own house (23.9\%) (Fig. 18.8). 


\section{COVID-19, Before Alert Level "Red"}
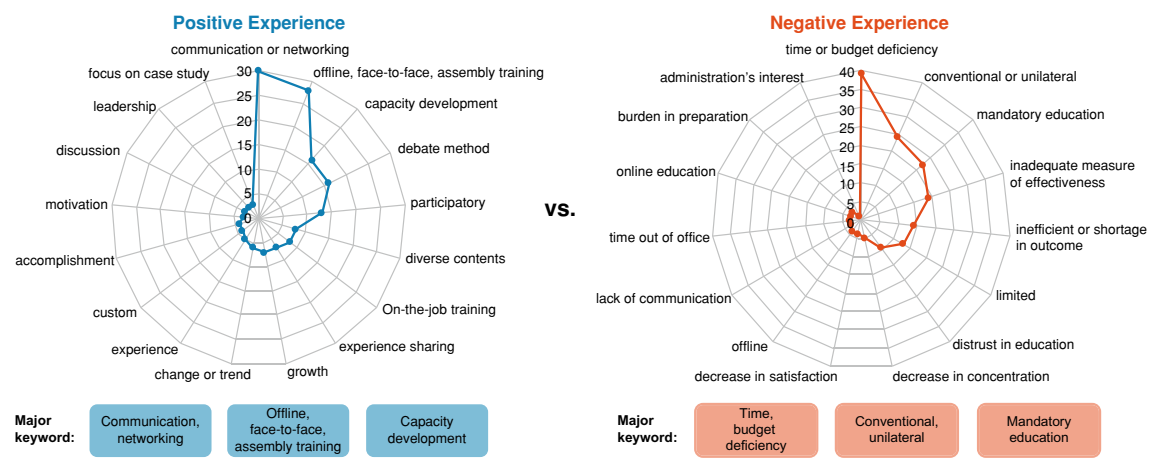

Fig. 18.6 Comparison between positive and negative experience before elevation of alert level to "red" (Prior to the COVID-19 level 3 alert, "communication and/or networking" are the top keywords with a positive association in human resource development, while "offline, face-to-face, assembly training" were the top keywords associated with negative attributes). COVID-19= coronavirus disease. Notes $N=196$ cases. 23 February 2020 is the cutoff date for "prior to elevation of COVID alert level to 'red'." Source Lee, C. 2020c. Vocational competency development and employment prospects in Korea after COVID-19. Paper presented in the 2020 ASEAN+3 HRD Forum, Human Resources Development Service of Korea, Republic of Korea, 17 November

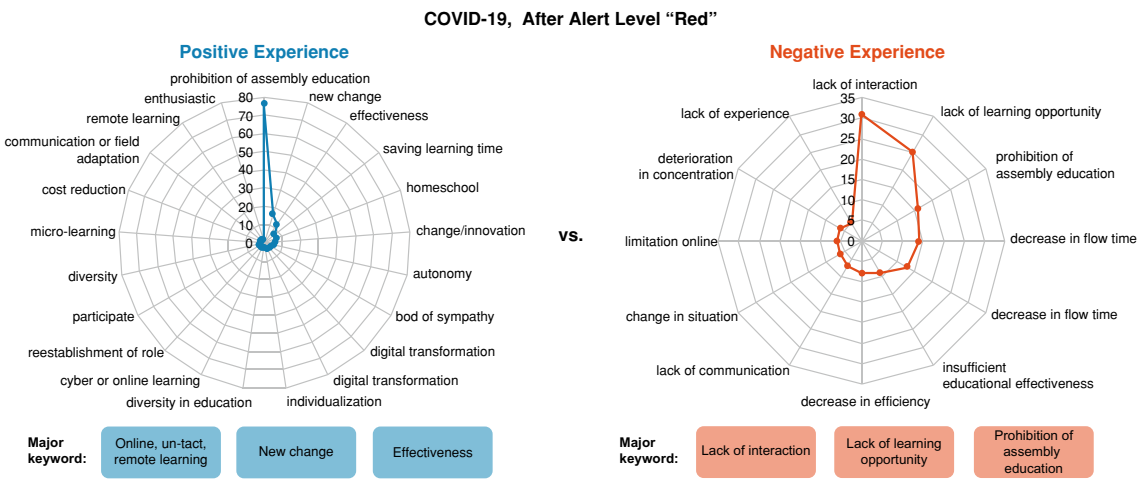

Fig. 18.7 Comparison between positive and negative experiences on human resource development, after the elevation of alert levels to "red" (After the COVID-19 level 3 alert, what used to be negative attributes such as "online, no contact, and remote learning" became positive attributes). Note Total cases reporting positive experiences $=188$ cases; total for negative experiences $=195$ cases. 23 February 2020 is the cutoff date for "prior to elevation of COVID alert level to 'red'." Source Lee, C. 2020c. Vocational competency development and employment prospects in Korea after COVID-19. Paper presented in the 2020 ASEAN+3 HRD Forum, Human Resources Development Service of Korea, Republic of Korea, 17 November 


\section{Major Progress of Scheduled Education}

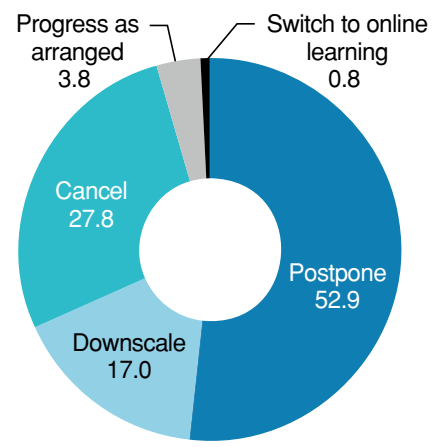

\section{Location for}

Studying

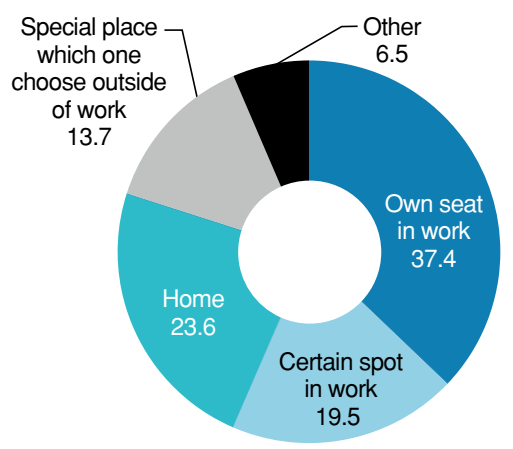

Fig. 18.8 Educational progress and learning location after the elevation to "red" (\%) (Education is quickly shifting to an online format). Source Lee, C. 2020b. The reality of work \& learning balance: WLB and the prospect of HRD in South Korea, post COVID-19. Korea Research Institute for Vocational Education and Training. The HRD Review 23 (3): 144-165

As can be seen from Fig. 18.8, education is quickly shifting into online format. The contents of the online curriculum are mostly delivered through e-Learning (45.5\%), and, in the case of the content platform, through Zoom (46.5\%) (Fig. 18.9).

\section{Provision Method for Online} Curriculum Contents

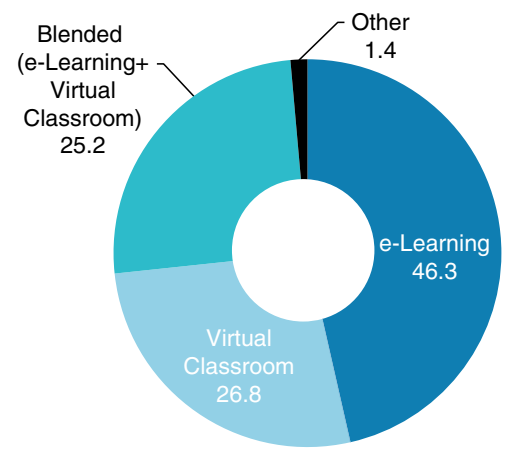

Platform for Curriculum Contents

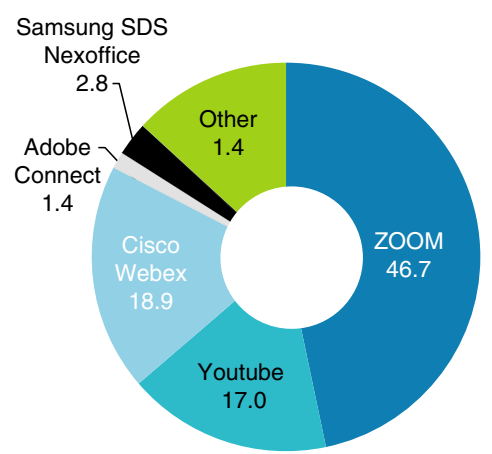

Fig. 18.9 Method and platform used to provide online curriculum contents after elevation to "red" (\%) (Curriculum delivery has become mostly through Zoom). Source Lee, C. 2020b. The reality of work \& learning balance: WLB and the prospect of HRD in South Korea, post COVID-19. Korea Research Institute for Vocational Education and Training. The HRD Review 23 (3): 144-165 


\subsubsection{Curriculum Quality}

On the aspect of curriculum quality, the results show that there is no prominent difference between the states before and after 23 February 2020; or if there was any, the degree was moderate with no particular dissatisfaction (43.4\%). Moreover, there were also responses of satisfaction $(29.2 \%)$, the reasons being the chance to have new experiences in online classes and the convenient nature of the online class itself. On the other hand, the reasons for dissatisfaction were decrease in educational feedback, limitations of operational process or contents development infrastructure, dismissal of learner's needs, and so on (Fig. 18.10).

\subsubsection{Cooperation and Collaboration}

Changes also occurred in methods of cooperation, one of which was the increase in online cooperation (63.2\%) since more work is now done at home. These online meetings are mostly done for business negotiations with other departments $(43.4 \%)$, work conferences between teams (30.7\%), and weekly business meetings $(28.8 \%)$ (Fig. 18.11).

The responses on satisfaction via collaboration using remote methods showed that the smoothness of the process was perceived as high (around 6.2 points), but compared to face-to-face work, in terms of effectiveness, it was low at 4.9 points out of 10 (see Fig. 18.12).

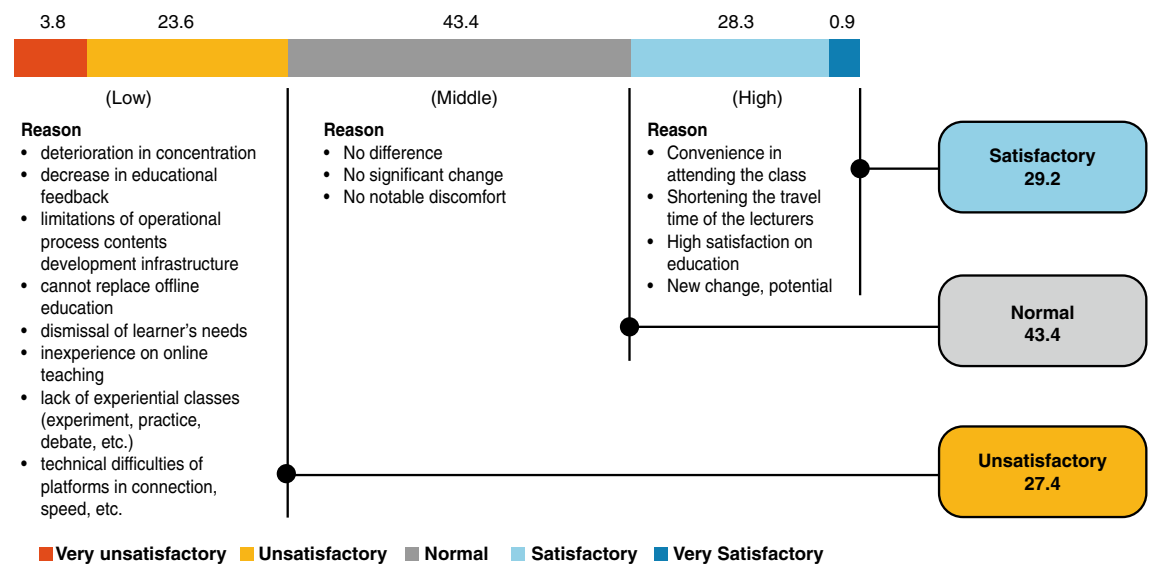

Fig. 18.10 Satisfaction rate on curriculum quality after elevation of alert level to "red" (\%) (The level of satisfaction for the curriculum has remained basically the same before and after the elevation to alert level 3). Source Lee, C. 2020b. The reality of work \& learning balance: WLB and the prospect of HRD in South Korea, post COVID-19. Korea Research Institute for Vocational Education and Training. The HRD Review 23 (3): 144-165 
Main Collaboration Strategies (including meetings etc.)

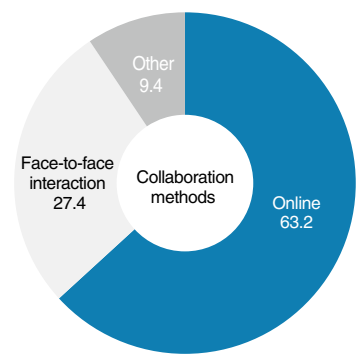

Main Goals of Online Collaboration

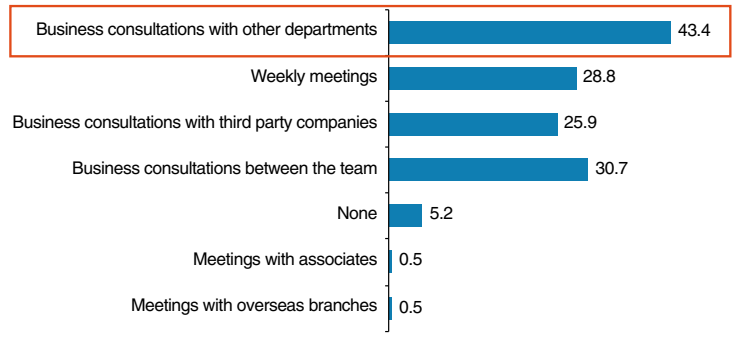

Fig. 18.11 Collaboration strategies and goals of online collaboration after elevation of alert level to "red" (\%) (With work now done mostly at home, online cooperation has increased). Notes "Others" include options such as face-to-face meetings, communication via email, refraining from meetings, etc. "Main goals of online collaboration" is a survey with multiple selection answers. Source Lee, C., and B. Park. 2020. Post COVID-19, survey on the actual condition of Korea about work \& learning balance (WLB). Paper presented in The Korean Society for Human Resource Development Annual Conference, Republic of Korea, 12 June

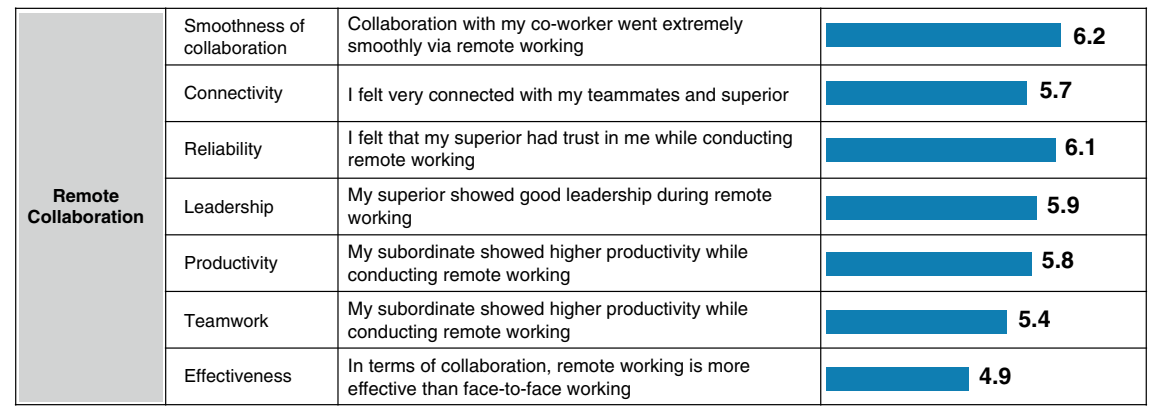

Fig. 18.12 Satisfaction on collaboration using remote methods after elevation of alert level to "red" (points) (While collaboration using remote methods was perceived as smooth, it was perceived as less effective compared to face-to-face work). Source Lee, C., and B. Park. 2020. Post COVID-19, survey on the actual condition of Korea about work \& learning balance (WLB). Paper presented in The Korean Society for Human Resource Development Annual Conference, Republic of Korea, 12 June

\subsubsection{Human Resource Development}

The survey results above indicate that the HRD environment has drastically changed after elevation to level 3 COVID-19 risk. Therefore, it is crucial to investigate the core abilities that are required while working in this new, remote working environment. An investigation was made regarding the abilities needed for oneself and one's superiors in this changed environment. Results showed that "abilities required for oneself" included digital proficiency $(55.7 \%)$, flexible thinking $(51.4 \%)$, and usage of 
data (31.6\%). Meanwhile, abilities required of a superior included flexible thinking (51.4\%), leadership (41.5\%), and digital proficiency (39.2\%) (see Fig. 18.13).

In the same survey, $82.9 \%$ of the participants replied that they had no experience working from home before the level alert was raised. However, after the elevation, the number decreased to $39.1 \%$ as participants reported working from home for 1 day (6.6\%), 2 days (9.9\%), 3 days (12.3\%), 4 days (4.3\%), and 5 days (7.5\%) of the week. Some worked from home for 1-4 days $(3.3 \%)$, while others reported intermittently working for the month (17\%) (see Fig. 18.14).

Before elevation to level 3, satisfaction about working from home was at $12.2 \%$, rising to $38.7 \%$ after the elevation (see Fig. 18.15).

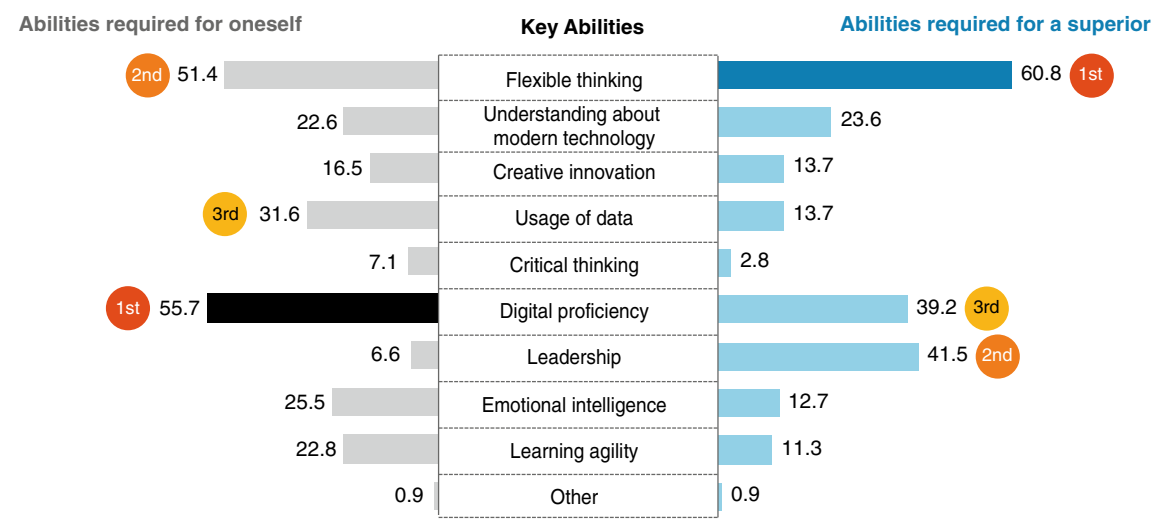

Fig. 18.13 Key abilities required for remote working after elevation of alert level to "red" (\%) (In the new, remote working environment, digital proficiency and flexible thinking rated highly as individual abilities one needs to acquire). Source Lee, C., and B. Park. 2020. Post COVID-19, survey on the actual condition of Korea about work \& learning balance (WLB). Paper presented in The Korean Society for Human Resource Development Annual Conference, Republic of Korea, 12 June

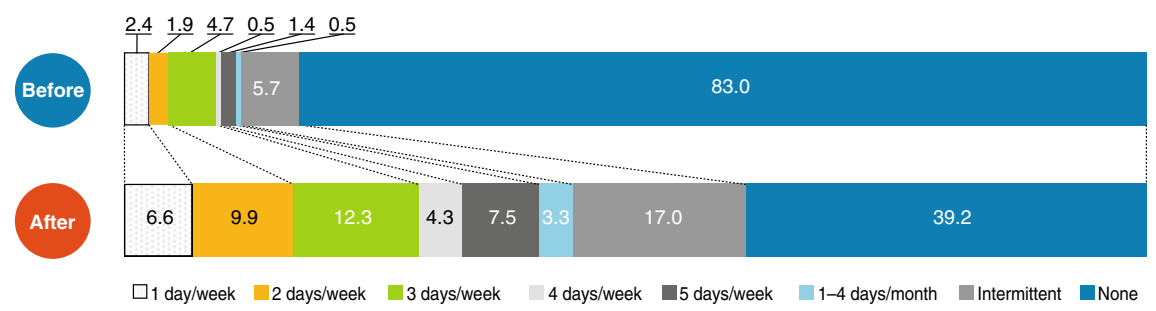

Fig. 18.14 Average number of days working from home per week before and after elevation of alert level to "red" (\%) (Before the level alert was raised, around 8 out of 10 had no experience working from home. After the elevation, most of the respondents reported working from home for 3 days). Source Lee, C. 2020a. Present and future of HRD. Paper presented in the HRD Conference, Human Resources Development Service of Korea, Republic of Korea, 10 September 


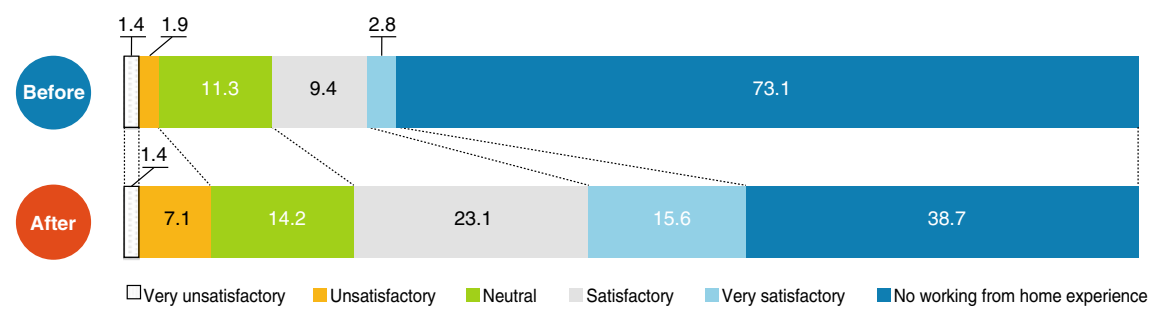

Fig. 18.15 Satisfaction on working from home before and after elevation of alert level to "red" (\%) (Satisfaction with working from home tripled after the elevation to level 3). Source Lee, C. 2020a. Present and future of HRD. Paper presented in the HRD Conference, Human Resources Development Service of Korea, Republic of Korea, 10 September

\subsection{Human Resource Development Trends in the Postcoronavirus Disease Era}

This study on HRD trends in the Republic of Korea before and after the elevation to level 3 suggests that the COVID-19 pandemic is bringing unprecedented changes to enterprises and organizations, and the effort to "change" in the HRD department is now an essential factor of survival. Due to COVID-19, there are new HRD trends appearing that are different from any other that have been experienced before, mainly in the form of changes in the way of education and in the way of working.

\subsubsection{Education}

The first HRD trend that must be noted is the change in the way of education. As seen in the surveys, collective, face-to-face learning before and after COVID-19 has shown an immense decrease of $64.1 \%$ from 66.5 to $2.4 \%$. As the traditional way of face-to-face collective learning is diminishing, it can be said that the trend in education is in a transition phase to becoming mainly online-based. Due to the ongoing developments in technology and more possible risks from the pandemic, it seems crucial to include digital literacy in the education curriculum, for which it is important to seek diversity and efficiency, as well as to maximize the learning effects of education in this online environment.

Furthermore, it is anticipated that the outbreak will change the traditional "education via professor" teaching method to focus on other methods such as blended learning and flipped learning. This moderated way of learning will essentially alter the role of schools and teachers, the teaching method, the evaluation of teaching methods, and the education environment, including facilities and equipment, demanding for innovative change. For this to happen, a proper study must happen on educational design, which has been overlooked by internal experts. The essential contents of 
online education must be strengthened and exactly curated. Box 18.1 is a case that shows a preemptive response in online learning.

\section{Box 18.1 DHL's Virtual Reality Education Program}

An illustration of preemptive response to the shift to online learning is the case of the logistics company DHL with its Virtual Reality (VR) education program. The VR practice program uses digital technology as a foundation, wherein internal experts analyze the organization's core abilities, incorporating these into training contents that are both safe and efficient. DHL is currently hosting a training program called CIS (Certified International Specialist) for individuals wishing to become international specialists. In this program, trainees gain general knowledge needed to become an international specialist, and the main four values that they must be conscious of as a member of DHL: Speed, Can Do, Passion, and Right 1st time.

What is notable in DHL's VR program is the fact that it used VR to create complicated simulations in the CIS process, allowing trainees to focus on their tasks. By doing so, VR technology and systematic competency analysis create an education program that not only increases productivity and gives workers self-satisfaction, but also provides quality education for DHL employees all over the world without time and location constraints.

Source DHL. Augmented and virtual reality. https://www.dhl.com/globalen/home/insights-and-innovation/thought-leadership/trend-reports/augmen ted-reality.html.

\subsubsection{Ways of Working}

Another new trend brought about by COVID-19 is the way people work. After the outbreak, the traditional commuting system put to place after industrialization changed to a new normal-the work-from-home-wherein existing working hours and commuting paradigms are changing. Initially practiced in information technology enterprises before the pandemic, other enterprises soon promoted work-from-home to stop the spread of COVID-19, an innovation to the old "working together face-to-face" culture in the office. In a survey conducted by the investigative agency Gartner among 317 American chief financial officers, 84\% responded "yes" to the question of whether they will continue to implement a work-from-home program even after the COVID-19 pandemic (Gartner 2020). Furthermore, according to the results from the Global Work-from-Home Experience Survey Report (Global Workplace Analytics 2020), 68\% of participants reported that working from home was very successful. 
Therefore, the future prospects in the way of working will have to develop into collaboration without spatial limitations, ultimately adjusting to a business-oriented performance management without constraints on time. Working trends changing to remote methods will allow for collaboration based on online connection without limitations on space, and working processes mainly based in the office will take place in a distributive manner. It is anticipated that working environments with no limitations to space will globally expand the scope of business. Box 18.2 depicts such a transition to work-from-home.

\section{Box 18.2 L Group's "Smart Offices"}

In the Republic of Korea, as of May 2020, the domestic enterprise L Group has initiated a "one day per week working from home" program, starting with L Holdings and L Shopping. The chairman of L Group is also participating in this work-from-home program, engaging in online meetings with overseas business establishments.

L Group has also formed several "smart-offices" in regions such as Ilsan, Incheon Terminal, Nowon, Pyeongchon, and Yeongdeungpo, allowing for a free commuting policy. For example, on Monday, one can work from home; on Tuesday and Wednesday, one can commute to the office; and on Thursday and Friday one can go to the "smart-offices".

Using a mixture of the "one day per week working from home" policy and the smart offices, L Group has established a working environment that is based on connection that goes beyond spatial limitations. Connectivity and collaboration in order to create value has been growing increasingly important with the changes in the working environment; thus, it is crucial to adapt to the rapidly changing new way of working that promotes remote management and skills in collaboration.

Source Chu, I. 2020. Shin Dong-bin's "work transformation" order...L Shopping's first base office (in Korean). JoongAng Ilbo. https://news.joins. com/article/23813604.

\subsubsection{Performance Management}

In a no-contact era, a change from the traditional performance evaluation to a task-oriented assessment is needed. As the concept of commuting is being increasingly reduced and a flexible working environment is on the rise, it is anticipated that the working attitude assessment concept will also decrease. Therefore to evaluate task performance it is crucial to consider other methods of evaluation such as absolute evaluation and frequent evaluation. Box 18.3 illustrates a new way of performance review. 


\section{Box 18.3: Adobe's “Absolute” Evaluation System}

Adobe is known for focusing on a performance management culture that will be needed in the postcoronavirus disease (COVID-19) era. In 2012, in order to change from an assessment method based on ranking to a performance-oriented evaluation, Adobe abolished its existing "relative" personnel evaluation system to an "absolute" evaluation system. Additionally, Adobe's "check-in" system allows for a performance evaluation that is based on direct communication and feedback between the administrators and employees without a personnel audit.

Through these two systems, employees are able to continuously check up with their managers about the business goals that have been set at the beginning of the year, actively altering the goals as they go along. The human resources department acts as human resource business partners for the managers, training and helping them in effectively using "check-in."

As was the case for Adobe, a shift has to be made from performance management to performance orientation in this rapidly changing environment due to the COVID-19 pandemic. Therefore, domestic enterprises that still adhere to the "relative evaluation system" that Jack Welch introduced in General Electric need to consider establishing a new and improved performance evaluation system.

Source Jung, E. 2018. Korea Adobe Systems “check-in” increases efficiency and activity in performance management (in Korean). https://www.hrinsight. co.kr/view/view.asp?in_cate=109\&gopage=1\&bi_pidx=27725.

\subsection{Key Abilities in the Postcoronavirus Disease Era}

\subsubsection{Empowering Leadership}

The first key ability in the new COVID-19 era is empowering leadership, which is grounded on trust in the capacity of employees. There have been worries that remote methods of work and education may cause anxiety within the leaders of groups. The reason for this is based on the opinion that if one cannot oversee, one might feel mistrust. However, changes in the working environment due to COVID-19 will have a huge effect on leaders and the leadership of organizations as well.

Empowering leadership may be defined as the act of a leader sharing authority with employees and constantly increasing the level of internal motivation (Srivastava et al. 2006). In transitioning to work-from-home, the time and space between the leaders and employees are divided, meaning that an organic leadership must be established via empowering leadership methods. At this time, it is necessary to explore ways to transform problematic structures such as having too many decision 
makers, interorganizational barriers, and boss-oriented organizational cultures into being more flexible and adaptable (agile) through empowering leadership. Among foreign companies, Amazon, Microsoft, and Netflix are pursuing to become agile organizations through frequent feedback and a smooth communication system.

\subsubsection{Digital Literacy}

Recently, the international community has recognized the importance of digital literacy and has been supporting national-level education and research to promote digital literacy among students (OECD 2019). First introduced by Gilster (1997), the importance of digital literacy has emerged from a type-based, read-write-oriented study to learning that includes new skills mediated by digital technology (Mills 2010). Kim (2019) defined digital literacy as an ability to understand the characteristics and messages of each media, and to discern the authenticity of information in various content usage. Therefore, such digital literacy is a very important capability in various social contexts and digital environments such as the workplace, school, and leisure.

While many opinions have referred to the fourth industrial revolution, digital transformation, etc., the importance of digital literacy for the digital transformation era has been recognized more during the past months of the COVID-19 pandemic than in the past few years. This is because business environments and education methods have been rapidly digitized. Futurelab in the United Kingdom saw digital literacy as a concept that synthesized technology, knowledge, and understanding that could be used critically, creatively, discerningly, and safely through the "digital literacy across the curriculum" (Futurelab 2010). The subcomponent of this consists of functional technology (information and communication technology), creativity, collaboration, communication, search for information, critical thinking, cultural and social understanding, and e-safety (being safe when being digitally active). In sum, the core of digital literacy can be seen as the ability to critically think about and utilize the opportunities and challenges offered by digital technology.

As mentioned above, digital literacy is no longer an ability required for software tasks alone, but has become the fundamental capability that all organization members should have. This is because the ability to discover and produce value using a large amount of information in a digital environment is essential (Han 2019). In addition, due to the spread of remote education, remote learning, and remote working environments, not only members of the organization but also the voices of the instructors within the company (who are essentially the digital literacy education channels), should be considered important. Likewise, recognition and compensation based on performance should be considered in terms of personnel management. 


\subsubsection{Learning Agility}

Learning agility refers to the ability and willingness to quickly and flexibly practice and implement what one has learned based on one's own experience in an unfamiliar, challenging situation (Lombardo and Eichinger 2000). In the wake of the digital transformation era, where digital transformation is accelerating and convergence is becoming common due to COVID-19, a talent development strategy is increasingly being required to overcome the skill gap. In other words, upskilling that allows learners to have the necessary capabilities, knowledge, and skills for post-COVID-19 times is growing more important, suggesting that learning agility (where learners master necessary knowledge and capabilities quickly and apply them to the workplace) is becoming essential.

\subsection{Conclusions: Directions in Human Resource Development in the Postcoronavirus Disease Era}

Considering the changes in education, work, and performance management methods since COVID-19 and reviewing each core competency, HRD's direction to move forward is as follows.

(i) The diversification of learning channels is necessary. In other words, as learning methods move toward utilizing online platforms, it is necessary to diversify learning content delivery methods to strengthen learners' immersion in learning. Content development should be accelerated to suit the concept. Content development and operation platforms will be needed to realize a new type of education in a timely manner.

(ii) Self-directed learning curation must be established. If there was a limit to the way collective education conveys a unified curriculum to learners, the online-oriented learning system can maximize the immersion of learning through a customized education design by subdividing the learner's experience.

(iii) Learning based on employee experience is needed. Existing HRD practices have segmented HR's detailed elements, such as recruitment, training, evaluation, compensation, and welfare from a supplier-oriented perspective. HRD in the new normal should change in the direction of designing and providing learning opportunities tailored to the individual experience of the employee. It is crucial to focus on the employees who are the consumers, and to consider the human resource elements that employees can experience from a comprehensive perspective.

(iv) Measurement of performance-oriented learning is called for. While the existing learning effect measurement focuses on completion of education and satisfaction, in the post-COVID-19 era, education must be designed so that it can be directly connected to work performance through learning. Measures 
should be prepared to evaluate learning performance rather than learning activity level.

(v) The balance between work and learning, or work-learning balance, should be considered. In the current no-contact era, rather than bringing learners to a training venue or an education center, HRD should enter the actual workplace in a digitally based manner. In other words, it is important to recognize the importance of field-oriented workplace learning. Considering the balance between work and learning is a task yet to be solved from the HRD perspective.

\section{References}

Cassie, H., and P. Sarah. 2010. Digital literacy across the curriculum. Bristol, UK: Futurelab. https:// www.nfer.ac.uk/publications/futl06/fut106.pdf.

Chu, I. 2020. Shin Dong-bin's “work transformation” order...L Shopping's first base office (in Korean). JoongAng Ilbo. https://news.joins.com/article/23813604.

DHL. Augmented and virtual reality. https://www.dhl.com/global-en/home/insights-and-innova tion/thought-leadership/trend-reports/augmented-reality.html.

Gartner. 2020. Gartner CFO survey reveals $74 \%$ intend to shift some employees to remote work permanently. 3 April. https://www.gartner.com/en/newsroom/press-releases/2020-04-03-gar tner-cfo-surey-reveals-74-percent-of-organizations-to-shift-some-employees-to-remote-workpermanently2.

Gilster, P. 1997. Digital literacy. New York: Wiley.

Global Workplace Analytics. 2020. Global work-from-home experience survey report. https://glo balworkplaceanalytics.com.

Han, H. 2019. A study on the analysis of digital literacy education and linkage to curriculum. Sejong City Institute of Education. Education Policy Research 4: 3-5.

International Labour Organization (ILO), UNESCO, and World Bank Group. 2020. ILO-UNESCO-WBG joint survey on technical and vocational education and training (TVET) and skills development during the time of COVID-19. Geneva: International Labour Organization.

International Labour Organization. 2020. ILO monitor: COVID-19 and the world of work, 2nd ed. ILO Briefing Note. No. 3. Geneva.

Jung, E. 2018. Korea Adobe Systems "check-in" increases efficiency and activity in performance management (in Korean). https://www.hrinsight.co.kr/view/view.asp?in_cate=109\&gopage=1\& bi_pidx=27725.

Kim, Y. 2019. Digital media literacy: Foreign case analysis and implications. National Assembly Research Service. NARS Current Issues and Analysis 90 (2).

Lee, C. 2020a. Present and future of HRD. Paper presented in the HRD Conference, Human Resources Development Service of Korea, Republic of Korea, 10 September.

Lee, C. 2020b. The reality of work \& learning balance: WLB and the prospect of HRD in South Korea, post COVID-19. Korea Research Institute for Vocational Education and Training. The HRD Review 23 (3): 144-165.

Lee, C. 2020c. Vocational competency development and employment prospects in Korea after COVID-19. Paper presented in the 2020 ASEAN+3 HRD Forum, Human Resources Development Service of Korea, Republic of Korea, 17 November.

Lee, C., and B. Park. 2020. Post COVID-19, survey on the actual condition of Korea about work \& learning balance (WLB). Paper presented in The Korean Society for Human Resource Development Annual Conference, Republic of Korea, 12 June. 
Lombardo, M.M., and E.R. Eichinger. 2000. High potential as high learners. Human Resources Management 39 (4): 321-330.

Mills, K.A. 2010. A review of the "digital turn" in the new literacy studies. Review of Educational Research 80 (2): 246-271.

Ministry of Employment and Labor. 2020. Labor market trends in March 2020 based on employment administration statistics. Seoul.

Organisation for Economic Co-operation and Development (OECD). 2019. Well-being in the digital age. OECD Going Digital Policy Note. Paris. https://www.oecd.org/going-digital/well-being-inthe-digital-age.pdf.

Song, C.H. 2020. Employment declined for five months... 1.14 million unemployed. Worst in 21 years (in Korean). DongAIlbo. A3. https://www.donga.com/news/article/all/20200813/102 427184/1.

Srivastava, A., K.M. Bartol, and E.A. Locke. 2006. Empowering leadership in management teams: Effects on knowledge sharing, efficacy, and performance. Academy of Management Journal 49 (6): 1239-1251.

Yang, M. 2020. The impact of Corona 19 on IT industry and social/economic (in Korean). DIGIECO. https://www.digieco.co.kr/KTFront/board/board_view.action?board_id= issue_trend\&board_seq=12932\#.

The opinions expressed in this chapter are those of the author(s) and do not necessarily reflect the views of the Asian Development Bank, its Board of Directors, or the countries they represent.

Open Access This chapter is licensed under the terms of the Creative Commons Attribution-NonCommercial 3.0 IGO license (http://creativecommons.org/licenses/by-nc/3.0/igo/) which permits any noncommercial use, sharing, adaptation, distribution and reproduction in any medium or format, as long as you give appropriate credit to the Asian Development Bank, provide a link to the Creative Commons license and indicate if changes were made.

Any dispute related to the use of the works of the Asian Development Bank that cannot be settled amicably shall be submitted to arbitration pursuant to the UNCITRAL rules. The use of the Asian Development Bank's name for any purpose other than for attribution, and the use of the Asian Development Bank's logo, shall be subject to a separate written license agreement between the Asian Development Bank and the user and is not authorized as part of this CC-IGO license. Note that the link provided above includes additional terms and conditions of the license.

The images or other third party material in this chapter are included in the chapter's Creative Commons license, unless indicated otherwise in a credit line to the material. If material is not included in the chapter's Creative Commons license and your intended use is not permitted by statutory regulation or exceeds the permitted use, you will need to obtain permission directly from the copyright holder.

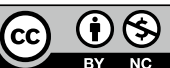

